\title{
A note on fuzzy PS-ideals in PS-algebra and its level subsets
}

\author{
T. Priya ${ }^{1 *}$, T. Ramachandran ${ }^{2}$ \\ ${ }^{1}$ Department of Mathematics, PSNA College of Engineering and Technology \\ ${ }^{2}$ Department of Mathematics, M.V.Muthiah Government Arts College for Women \\ *Corresponding author E-mail: tpriyasuriya@gmail.com
}

Copyright () 2014 T.Priya, T.Ramachandran. This is an open access article distributed under the Creative Commons Attribution License, which permits unrestricted use, distribution, and reproduction in any medium, provided the original work is properly cited.

\begin{abstract}
In this paper, a new notion, named fuzzification of PS - Algebra, which is a generalization of $\mathrm{BCK} / \mathrm{BCI} / \mathrm{TM} / \mathrm{BH} / \mathrm{Q} / \mathrm{d} / \mathrm{KU}$-algebras, is introduced, along with PS-ideal and we have discussed some of their properties in detail.
\end{abstract}

Keywords: PS-Algebra, PS-ideal, Fuzzy PS-Ideal, Level Subsets, PS-Subalgebra and Fuzzy PS-Subalgebra.

\section{Introduction}

The concept of fuzzy set was initiated by L.A.Zadeh in 1965 [15]. Since then these ideas have been applied to other algebraic structures such as groups, rings, modules, vector spaces and topologies. K.Iseki and S.Tanaka [2] introduced the concept of BCK-algebras in 1978 and K.Iseki [3] introduced the concept of BCI-algebras in 1980. It is known that the class of BCK -algebras is a proper subclass of the class of BCI algebras. J.Neggers and H.S.Kim introduced a notion called B-algebra in 2002. T.Priya and T.Ramachandran [8-13] introduced the new algebraic structure, PSalgebra, which is an another generalization of BCI / BCK/Q /d/ KU algebras and investigated its properties in detail. In this paper we introduce a new notion, called fuzzification of PS-algebra, which is a generalization of BCK / BCI / BH/Q /d /TM / KU algebras, and investigate some of its properties.

\section{Preliminaries}

In this section we site the fundamental definitions that will be used in the sequel.

Definition 2.1 [2]: A BCK-algebra is an algebra $(X, *, 0)$ of type $(2,0)$ satisfying the following conditions:

i) $\quad(\mathrm{x} * \mathrm{y}) *(\mathrm{x} * \mathrm{z}) \leq(\mathrm{z} * \mathrm{y})$

ii) $\mathrm{x} *(\mathrm{x} * \mathrm{y}) \leq \mathrm{y}$

iii) $\mathrm{x} \leq \mathrm{x}$

iv) $\mathrm{x} \leq \mathrm{y}$ and $\mathrm{y} \leq \mathrm{x} \Rightarrow \mathrm{x}=\mathrm{y}$

v) $0 \leq x \Rightarrow x=0$, where $\mathrm{x} \leq \mathrm{y}$ is defined by $\mathrm{x} * \mathrm{y}=0$, for all $\mathrm{x}, \mathrm{y}, \mathrm{z} \in \mathrm{X}$

Definition 2.2 [3]: A BCI- algebra is an algebra $(X, *, 0)$ of type $(2,0)$ satisfying the following conditions:

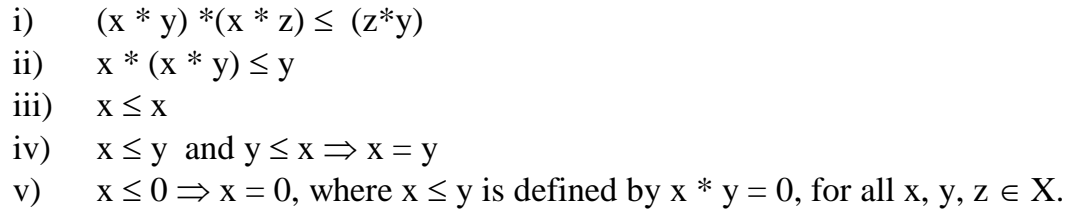

Definition 2.3 [5]: A $Q$ - algebra is an algebra $\left(X,{ }^{*}, O\right)$ of type $(2,0)$ satisfying the following conditions:

i) $\quad \mathrm{x} * \mathrm{x}=0$
$\mathrm{x} * 0=\mathrm{x}$ 
iii) $\quad(\mathrm{x} * \mathrm{y}) * \mathrm{z}=(\mathrm{x} * \mathrm{z}) * \mathrm{y}$, where $\mathrm{x} \leq \mathrm{y}$ is defined by $\mathrm{x} * \mathrm{y}=0$, for all $\mathrm{x}, \mathrm{y}, \mathrm{z} \in \mathrm{X}$.

Definition 2.4 [6]: A $d$ - algebra is an algebra $(X, *, 0)$ of type(2,0) satisfying the following conditions:

i) $\quad x * x=0$

ii) $0 * \mathrm{x}=0$

iii) $\mathrm{x} * \mathrm{y}=0$ and $\mathrm{y} * \mathrm{x}=0$ imply $\mathrm{x}=\mathrm{y}$, for all $\mathrm{x}, \mathrm{y} \in \mathrm{X}$.

Definition 2.5 [7,14]: A KU-algebra is an algebra $\left(X,{ }^{*}, 0\right)$ of type $(2,0)$ satisfying the following conditions:

i) $\quad(\mathrm{x} * \mathrm{y}) *((\mathrm{y} * \mathrm{z}) *(\mathrm{x} * \mathrm{z}))=0$

ii) $\mathrm{x} * 0=0$

iii) $0 * \mathrm{x}=\mathrm{x}$

iv) $\mathrm{x} * \mathrm{y}=0$ and $\mathrm{y} * \mathrm{x}=0$ imply $\mathrm{x}=\mathrm{y}$, for all $\mathrm{x}, \mathrm{y}, \mathrm{z} \in \mathrm{X}$.

Remark:

- $\quad$ Every BCK-algebra is a TM-algebra but not the converse.

- $\quad$ Every BCK-algebra is a BCI-algebra but not the converse.

- $\quad$ Every BCI-algebra is a BCH-algebra but not the converse.

- $\quad$ Every BCH-algebra is a Q-algebra but not the converse.

- $\quad$ Every TM-algebra is a BH-algebra but not the converse.

- $\quad$ Every BCK-algebra is a d-algebra but not the converse.

Definition 2.6 [8]: Let $S$ be a non-empty subset of an algebra $X$, then $S$ is called a subalgebra of $X$ if $x * y \in S, \quad$ for all $x, y \in S$.

Definition 2.7 [15]: Let $X$ is a non-empty set. A fuzzy subset $\mu$ of the set $X$ is a mapping $\mu: X \rightarrow[0,1]$.

Definition 2.8 [9]: Let $\mu$ be a fuzzy set of $X$. For a fixed $t \in[0,1]$, the set $\mu^{t}=\{x \in X / \mu(x) \geq t\}$ is called the upper level subset of $\mu$. Clearly $\mu^{t} \cup \mu_{t}=X$ for $t \in[0,1]$ if $t_{1}<t_{2}$, then $\mu_{t 1} \subseteq \mu_{t 2}$.

\section{Fuzzy PS-ideal and Fuzzy PS-Sub algebra}

Definition 3.1 (PS-algebra): A nonempty set $X$ with a constant 0 and a binary operation ' * 'is called PS - Algebra if it satisfies the following axioms.

1. $\mathrm{x} * \mathrm{x}=0$

2. $\mathrm{x} * 0=0$

3. $\quad \mathrm{x} * \mathrm{y}=0$ and $\mathrm{y} * \mathrm{x}=0 \Rightarrow \mathrm{x}=\mathrm{y}, \forall \mathrm{x}, \mathrm{y} \in \mathrm{X}$.

In $\mathrm{X}$, we define a binary relation $\leq$ by $\mathrm{x} \leq \mathrm{y}$ if and only if $\mathrm{y} * \mathrm{x}=0$.

In any PS-algebra $(X, *, 0)$, the following holds good for all $\mathrm{x}, \mathrm{y} \in \mathrm{X}$.

1. $\mathrm{x} *(\mathrm{y} * \mathrm{x})=\mathrm{y} *(\mathrm{x} * \mathrm{x})$

2. $\mathrm{y} *\left(\mathrm{x} *\left(\mathrm{y}^{*} \mathrm{x}\right)\right)=0$

3. $\mathrm{x} *(\mathrm{x} *(\mathrm{x} * \mathrm{y}))=\mathrm{x} * \mathrm{y}$

4. $\mathrm{y} *(\mathrm{x} *(\mathrm{x} * \mathrm{y}))=0$

Example 3.1: Let $X=\{0, a, b, c\}$ be the set with the following Cayley table.

\begin{tabular}{|l|l|l|l|l|}
\hline$*$ & 0 & $\mathrm{a}$ & $\mathrm{b}$ & $\mathrm{c}$ \\
\hline 0 & 0 & $\mathrm{~b}$ & $\mathrm{a}$ & $\mathrm{c}$ \\
\hline $\mathrm{a}$ & 0 & 0 & 0 & $\mathrm{~b}$ \\
\hline $\mathrm{b}$ & 0 & 0 & 0 & $\mathrm{~b}$ \\
\hline $\mathrm{c}$ & 0 & $\mathrm{~b}$ & $\mathrm{~b}$ & 0 \\
\hline
\end{tabular}

Then $(\mathrm{X}, *, 0)$ is a PS - algebra.

Remark: Every KU algebra is a PS-algebra but not the converse, since $\left(a^{*} 0\right) *((0 * c) *(a * c))=a \neq 0$.

Definition 3.2: Let X be a PS-algebra and I be a subset of X, then I is called a PS-ideal of X if it satisfies the following conditions:

1. $0 \in \mathrm{I}$

2. $\mathrm{y} * \mathrm{x} \in \mathrm{I}$ and $\mathrm{y} \in \mathrm{I} \Rightarrow \mathrm{x} \in \mathrm{I}$ 
Definition 3.3: Let $X$ be a PS-algebra. A fuzzy set $\mu$ in $X$ is called a fuzzy PS-ideal of X if it satisfies the following conditions.

i) $\quad \mu(0) \geq \mu(\mathrm{x})$

ii) $\quad \mu(\mathrm{x}) \geq \min \{\mu(\mathrm{y} * \mathrm{x}), \mu(\mathrm{y})\}$, for all $\mathrm{x}, \mathrm{y} \in \mathrm{X}$

Definition 3.4: A fuzzy set $\mu$ in a PS-algebra $X$ is called a fuzzy $P S$ - sub algebra of $X$ if $\mu(x * y) \geq \min \{\mu(x), \mu(y)\}$, for all $x, y \in X$.

Theorem 3.1: Every fuzzy PS-ideal of a PS-algebra X is order reversing.

Proof: Let $\mu$ be a fuzzy PS-ideal of a PS-algebra X and let $x, y \in X$ be such that $\mathrm{x} \leq \mathrm{y}$, then $\mathrm{y} * \mathrm{x}=0$

Now $\mu(\mathrm{x}) \geq \min \{\mu(\mathrm{y} * \mathrm{x}), \mu(\mathrm{y})\}$

$$
\begin{aligned}
& =\min \{\mu(0), \mu(\mathrm{y})\} \\
& =\{\mu(\mathrm{y})\} \\
\Rightarrow \mu(\mathrm{x}) \geq & \mu(\mathrm{y})
\end{aligned}
$$

Theorem 3.2: If $\mu$ is a fuzzy PS-ideal then it satisfies the condition $\mu(x *(y * x)) \geq \mu(y)$.

Proof : Let $\mu$ be a fuzzy PS-ideal. Then

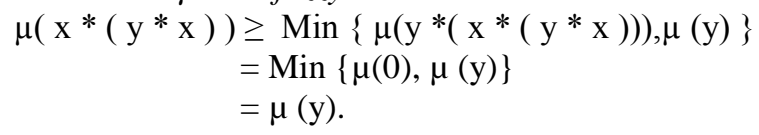

Theorem 3.3: Let $X$ be a PS-algebra. $\mu$ is a fuzzy PS-ideal of X iff $\mu$ is a fuzzy PS-subalgebra of X.

Proof: By definition, every fuzzy PS-ideal of a PS-algebra X is a fuzzy PS-subalgebra of X.

Let $\mu$ be a fuzzy PS-ideal.

To prove: $\mu$ is a fuzzy PS- subalgebra of $X$.

By definition of PS-ideal, $\mu(x) \geq \min \{\mu(y * x), \mu(y)\}$, for all $x, y \in X$

Now $\mu\left(x^{*} y\right) \geq \min \{\mu(y *(x * y), \mu(y)\}$,

$$
\begin{aligned}
& =\min \{\mu(0), \mu(y)\} \\
& \geq \min \{\mu(\mathrm{x}), \mu(\mathrm{y})\}
\end{aligned}
$$

$\Rightarrow \mu$ is a fuzzy PS- subalgebra of $X$.

Conversely, let $\mu$ be a fuzzy PS-subalgebra of X.

To prove: $\mu$ is a fuzzy PS-ideal of $X$

Now $\mu(0)=\mu(\mathrm{x} * \mathrm{x})$

$$
\geq \min \{\mu(x), \mu(x)\}
$$

$$
=\mu(\mathrm{x})
$$

$\Rightarrow \mu(0) \geq \mu(\mathrm{x})$

$$
\text { And } \begin{aligned}
\mu(\mathrm{x}) & \geq \mu(\mathrm{y}) \\
& =\min \{\mu(0), \mu(\mathrm{y})\} \\
& =\min \{\mu(\mathrm{y} * \mathrm{x}), \mu(\mathrm{y})\}
\end{aligned}
$$

$\Rightarrow \mu(\mathrm{x}) \geq \min \{\mu(\mathrm{y} * \mathrm{x}), \mu(\mathrm{y})\}$

Hence $\mu$ is a fuzzy PS-ideal of $X$.

Theorem 3.4: The intersection of any set of fuzzy PS-ideal in PS-algebra X is also a fuzzy PS-ideal.

Proof: Let $\left\{\mu_{i}\right\}$ be a family of fuzzy PS-ideals of PS-algebras X.

Then for any $\mathrm{x}, \mathrm{y} \in \mathrm{X}$.

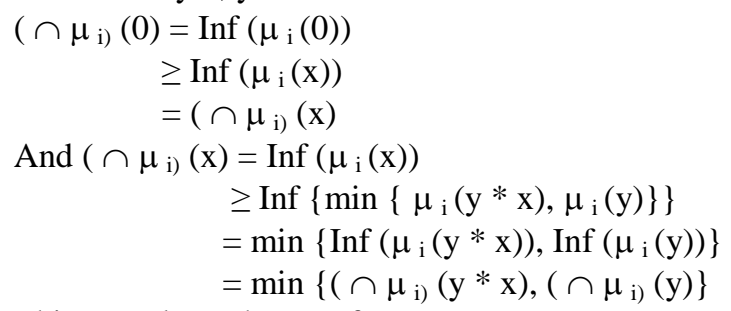

This completes the proof.

Theorem 3.5: A fuzzy set $\mu$ of a PS-algebra X is a fuzzy PS-subalgebra iff for every $t \in[0,1], \mu^{t}$ is either empty or a subalgebra of $X$.

Proof: Assume that $\mu$ is a fuzzy PS- sub algebra of $X$ and $\mu^{t} \neq \phi$

Then for any $\mathrm{x}, \mathrm{y} \in \mu^{\mathrm{t}}$, we have 
$\mu(\mathrm{x} * \mathrm{y}) \geq \min \{\mu(\mathrm{x}), \mu(\mathrm{y})\}=\mathrm{t}$

There fore $\mathrm{x} * \mathrm{y} \in \mu^{\mathrm{t}}$

Hence $\mu^{\mathrm{t}}$ is a sub algebra of $X$.

Conversely, assume that $\mu^{t}$ is subalgebra of $X$.

Let $\mathrm{x}, \mathrm{y} \in \mathrm{X}$. Take $\mathrm{t}=\min \{\mu(\mathrm{x}), \mu(\mathrm{y})\}$

Then by assumption $\mu^{t}$ is a sub algebra of $X, x * y \in \mu^{t}$

$\mu(\mathrm{x} * \mathrm{y}) \geq \mathrm{t}=\min \{\mu(\mathrm{x}), \mu(\mathrm{y})\}$

Hence $\mu$ is a fuzzy PS- sub algebra of $X$.

Theorem 3.6: Any sub algebra of a PS - algebra X can be realized as level sub algebra of some fuzzy PS-sub algebra of $X$.

Proof: Let $\mu$ be a sub algebra of the given PS-algebra X and let $\mu$ be a fuzzy set in $X$ defined by

$\mu(x)=t$, if $x \in A$

0 , if $x \notin A$.

where $t \in[0,1]$ is fixed. It is clear that $\mu^{\mathrm{t}}=\mathrm{A}$.

Now we prove such defined $\mu$ is a fuzzy PS- sub algebra of $\mathrm{X}$.

Let $\mathrm{x}, \mathrm{y} \in \mathrm{X}$. If $\mathrm{x}, \mathrm{y} \in \mathrm{A}$, then $\mathrm{x}^{*} \mathrm{y} \in \mathrm{A}$.

Hence $\mu(x)=\mu(y)=\mu(x * y)=t$ and $\mu(x * y) \geq \min \{\mu(x), \mu(y)\}$

If $\mathrm{x}, \mathrm{y} \notin \mathrm{A}$, then $\mu(\mathrm{x})=\mu(\mathrm{y})=0$ and $\mu(\mathrm{x} * \mathrm{y}) \geq \min \{\mu(\mathrm{x}), \mu(\mathrm{y})\}=0$.

If at most one of $\mathrm{x}, \mathrm{y} \in \mathrm{A}$, then at least one of $\mu(\mathrm{x})$ and $\mu(\mathrm{y})$ is equal to 0 .

Therefore, $\min \{\mu(\mathrm{x}), \mu(\mathrm{y})\}=0$ so that $\mu(\mathrm{x} * \mathrm{y}) \geq 0$, which completes the proof.

As a generalisation of theorem 3.6, we prove the following theorem.

Theorem 3.7 : Let $X$ be à PS- algebra. Then given any chain of subalgebra $S_{0} \subset S_{1} \subset S_{2} \subset$ $\subset S_{r}=X$

there exists a fuzzy PS-subalgebra $\mu$ of $X$ whose level subalgebras are exactly the sualgebras of this chain.

Proof : Consider a set of numbers $t_{0}>t_{1}>t_{2}>\ldots \ldots \ldots>t_{r}$, where each $t_{i} \in[0,1]$.

Let $\mu: X \rightarrow[0,1]$ be a fuzzy set defined by $\mu\left(s_{0}\right)=t_{0}$ and $\mu\left(s_{i}-s_{i-1}\right)=t_{i}, 0<i \leq r$.

We claim that $\mu$ is a fuzzy PS-subalgebra of X.Let $x, y \in X$. Then we classify it into two cases as follows :

Case (1)

Let $\mathrm{x}, \mathrm{y} \in \mathrm{s}_{\mathrm{i}}-\mathrm{s}_{\mathrm{i}-1}$. Then by the definition of $\mu$,

$\mu(\mathrm{x})=\mathrm{t}_{\mathrm{i}}=\mu(\mathrm{y})$.

Since $S_{\mathrm{i}}$ is a subalgebra, it follows that $\mathrm{x} * \mathrm{y} \in \mathrm{S}_{\mathrm{i}}$, and so either $\mathrm{x} * \mathrm{y} \in \mathrm{S}_{\mathrm{i}}-\mathrm{S}_{\mathrm{i}-1}$ (or) $\mathrm{x} * \mathrm{y} \in \mathrm{S}_{\mathrm{i}-1}$

In any case, we conclude that

$\mu(\mathrm{x} * \mathrm{y}) \geq \mathrm{t}_{\mathrm{i}}=\min \{\mu(\mathrm{x}), \mu(\mathrm{y})\}$.

Case (2)

For $\mathrm{i}>\mathrm{j}$,

Let $\mathrm{x} \in \mathrm{S}_{\mathrm{i}}-\mathrm{S}_{\mathrm{i}-1}$ and $\mathrm{y} \in \mathrm{S}_{\mathrm{j}}-\mathrm{S}_{\mathrm{j}-1}$.

Then $\mu(x)=t_{i} ; \mu(y)=t_{j}$ and $x * y \in S_{i}$, since $S_{i}$ is a subalgebra of $X$ and $S_{j} \subset S_{i}$.

Hence $\mu(x * y) \geq t_{j}=\min \{\mu(x), \mu(y)\}$

Thus $\mu$ is a fuzzy PS-subalgebra of $X$.

From the definition of $\mu$,it follows that $\operatorname{Im}(\mu)=\left\{t_{0}, t_{1}, t_{2}, \ldots \ldots t_{r}\right\}$.

Hence the level subalgebras of $\mu$ are given by the chain of subalgebras.

$\mu_{\mathrm{t} 0} \subset \mu_{\mathrm{t} 1} \subset \mu_{\mathrm{t} 2} \subset \ldots \ldots \ldots \ldots . . \mu_{\mathrm{tr}}=\mathrm{X}$.

Now $\mu_{\mathrm{t} 0}=\left\{\mathrm{x} \in \mathrm{X} / \mu(\mathrm{x}) \geq \mathrm{t}_{0}\right\}=\mathrm{S}_{0}$.

Finally, we prove that $\mu_{\mathrm{ti}}=\mathrm{S}_{\mathrm{i}}$ for $0<\mathrm{i} \leq \mathrm{r}$.

Clearly $\mathrm{S}_{\mathrm{i}} \subseteq \mu_{\mathrm{ti}}$.

If $x \in \mu_{t i}$, then $\mu(x) \geq t_{i}$ which implies that $x \notin S_{j}$ for $j>i$.

Hence $\mu(x) \in\left\{t_{1}, t_{2}, \ldots \ldots \ldots t_{i}\right\}$ and so $x \in S_{k}$ for some $k \leq i$.

As $\mathrm{S}_{\mathrm{k}} \subseteq \mathrm{S}_{\mathrm{i}}$, it follows that $\mathrm{x} \in \mathrm{S}_{\mathrm{i}}$.

$\Rightarrow \mu_{\mathrm{ti}}=\mathrm{S}_{\mathrm{i}}$ for $0<\mathrm{i} \leq \mathrm{r}$.

This completes the proof.

Theorem 3.8: Two level sub algebras $\mu^{s}, \mu^{t}(s<t)$ of a fuzzy PS-sub algebras are equal iff there is no $x \in X$ such that $s \leq \mu(x)<t$.

Proof: Let $\mu^{s}=\mu^{t}$ for some $s<t$. If there exist $x \in X$ such that $s \leq \mu(x)<t$, then $\mu^{t}$ is a proper subset of $\mu^{s}$, which is a contradiction.

Conversely, assume that there is no $\mathrm{x} \in \mathrm{X}$ such that $\mathrm{s} \leq \mu(\mathrm{x})<\mathrm{t}$.

Since $\mathrm{s}<\mathrm{t}, \mu^{\mathrm{t}} \subseteq \mu^{\mathrm{s}}$.

If $\mathrm{x} \in \mu^{\mathrm{s}}$, then $\mu(\mathrm{x}) \geq \mathrm{s}$ and so $\mu(\mathrm{x}) \geq \mathrm{t}$, because $\mu(\mathrm{x})$ does not lie between $\mathrm{s}$ and $\mathrm{t}$. 
Hence $\mathrm{x} \in \mu^{\mathrm{t}}$, which gives $\mu^{\mathrm{s}} \subseteq \mu^{\mathrm{t}}$.

This completes the proof.

Theorem 3.9: Let $\mu$ be a fuzzy set in a PS-algebra X and let $t \in \operatorname{Im}(\mu)$. Then $\mu$ is a fuzzy PS-ideal of $X$ if and only if the level subset $\mu^{t}$ is a PS-ideal of $X$, which is called a level PS-ideal of $X$.

Proof: Assume that $\mu$ is a fuzzy PS-ideal of X. Clearly $0 \in \mu^{t}$.

Let $\mathrm{y} * \mathrm{x} \in \mu^{\mathrm{t}}$ and $\mathrm{y} \in \mu^{\mathrm{t}}$. Then $\mu(\mathrm{y} * \mathrm{x}) \geq \mathrm{t}$ and $\mu(\mathrm{y}) \geq \mathrm{t}$

Now $\mu(x) \geq \min \{\mu(y * x), \mu(y)\}$

$$
\begin{aligned}
& \geq \min \{\mathrm{t}, \mathrm{t}\} \\
& =\mathrm{t}
\end{aligned}
$$

Hence the level subset $\mu^{\mathrm{t}}$ is a PS-ideal of X.

Conversely assume that, the level subset $\mu^{t}$ is a PS-ideal of $X$, for any $t \in[0,1]$.

Suppose assume that there exist some $\mathrm{x}_{0} \in \mathrm{X}$ such that $\mu(0)<\mu\left(\mathrm{x}_{0}\right)$

Take $\mathrm{s}=\frac{1}{2}\left[\mu(0)+\mu\left(\mathrm{x}_{0}\right)\right]$

$\Rightarrow \mu(0)<\mathrm{s}<\mu\left(\mathrm{x}_{0}\right)$

$\Rightarrow \mathrm{x}_{0} \in \mu^{\mathrm{s}}$ and $0 \notin \mu^{\mathrm{s}}$, a contradiction, since $\mu^{\mathrm{s}}$ is a PS-ideal of X.

Therefore, $\mu(0) \geq \mu(x)$ for all $x \in X$.

If possible, assume that $\mathrm{x}_{0}, \mathrm{y}_{0} \in \mathrm{X}$ such that $\mu\left(\mathrm{x}_{0}\right)<\min \left\{\mu\left(\mathrm{y}_{0} * \mathrm{x}_{0}\right), \mu\left(\mathrm{y}_{0}\right)\right\}$.

Take $\mathrm{s}=\frac{1}{2}\left[\mu\left(\mathrm{x}_{0}\right)+\min \left\{\mu\left(\mathrm{y}_{0} * \mathrm{x}_{0}\right), \mu\left(\mathrm{y}_{0}\right)\right\}\right]$

$\Rightarrow \mathrm{s}>\mu\left(\mathrm{x}_{0}\right)$ and $\mathrm{s}<\min \left\{\mu\left(\mathrm{y}_{0} * \mathrm{x}_{0}\right), \mu\left(\mathrm{y}_{0}\right)\right\}$.

$\Rightarrow \mathrm{s}>\mu\left(\mathrm{x}_{0}\right), \mathrm{s}<\mu\left(\mathrm{y}_{0} * \mathrm{x}_{0}\right)$ and $\mathrm{s}<\mu\left(\mathrm{y}_{0}\right)$.

$\Rightarrow \mathrm{x}_{0} \notin \mu^{\mathrm{s}}$, a contradiction, since $\mu^{\mathrm{s}}$ is a PS-ideal of X.

Therefore $\mu(x) \geq \min \{\mu(y * x), \mu(y)\}$, for any $x, y \in X$.

Theorem 3.10 : Let $X$ be a PS-algebra \& $\mu$ be a fuzzy PS-subalgebra of $X$. If $\operatorname{Im}(\mu)$ is finite, say $\left\{t_{1}, t_{2}, \ldots, t_{r}\right.$, , then for any $t_{i}, t_{j} \in \operatorname{Im}(\mu), \mu_{\mathrm{t}_{\mathrm{i}}}=\mu_{\mathrm{t}_{\mathrm{j}}}$, implies $t_{i}=t_{j}$.

Proof : Assume that $t_{i} \neq t_{j}$ say $t_{i}<t_{j}$.

If $\mathrm{x} \in \mu_{\mathrm{t}_{\mathrm{i}}}$ then $\mu(\mathrm{x}) \geq \mathrm{t}_{\mathrm{j}}>\mathrm{t}_{\mathrm{i}}$, which implies that $\mathrm{x} \in \mu_{\mathrm{t}_{\mathrm{i}}}$.

Let $x \in X$ be such that $t_{i}<\mu(x)<t_{j}$

Then $\mathrm{x} \in \mu_{\mathrm{t}_{\mathrm{i}}}$, but $\mathrm{x} \notin \mu_{\mathrm{t}_{\mathrm{i}}}$.

Hence $\mu_{\mathrm{t}_{\mathrm{j}}} \not \subset \mu_{\mathrm{t}_{\mathrm{i}}}$ and $\mu_{\mathrm{t}_{\mathrm{i}}}=\mu_{\mathrm{t}_{\mathrm{i}}}$, a contradiction.

\section{Conclusion}

In this article authors have been discussed fuzzy PS-ideal in fuzzy PS-algebra. The relationship between level subsets and subalgebra also established. It has been observed that PS-algebra as a generalization of BCK/BCI/Q/d/TM/KUalgebras. Interestingly, the chain concept adds another dimension to the defined PS-algebra. This concept can further be generalized to Intuitionistic fuzzy set, interval valued fuzzy sets, Lie algebra for new results in our future work.

\section{Acknowledgement}

Authors wish to thank Dr. K.T.Nagalakshmi, Professor and Head ,Department of Mathematics, K L N College of Information and Technology, Pottapalayam, Sivagangai District, Tamilnadu, India, and Prof. P.M.Sithar Selvam, Department of Mathematics, PSNA College of Engineering and Technology, Dindigul, Tamilnadu , India, for their help to make this paper as successful one.

\section{References}

[1] Hu Q.P. and Li X. , On BCH-algebras, Mathematics Seminar notes11 (1983), 313-320.

[2] Iseki K. and Tanaka S., An introduction to the theory of BCK - algebras , Math Japonica 23 (1978), 1- 20

[3] Iseki K., On BCI-algebras, Math.Seminar Notes 8 (1980), 125-130.

[4] Megalai K.and Tamilarasi A.,Fuzzy Subalgebras and Fuzzy T-ideals in TM-algebra, Journal of Mathematics and Statistics 7(2),2011,107-111.

[5] Neggers. J, Ahn S.S. and Kim H.S., On Q-algebras, IJMMS 27 (2001), 749-757.

[6] Neggers.J and Kim H.S., On d-algebras, Math,slovaca, 49 (1999) , 19-26

[7] Prabpayak C. and Leerawat U.,On Ideals and congurences in KU-algebras, Scientia Magna J. 5(1)(2009),54-57. 
[8] Priya T. and Ramachandran T., Classification of PS-algebras, The International Journal of Science and Technoldge, Communicated.

[9] Priya T. and Ramachandran T., Some properties of fuzzy dot PS-sub algebras of PS-algebras, Annals of Pure and Applied Mathematics, Vol.6, No.1, 2014, 11-18.

[10] Priya T. and Ramachandran T. , Some Characterization of Anti-fuzzy PS-ideals of PS-algebras in Homomorphism and Cartesian Products , International Journal of Fuzzy Mathematical Archive, Vol.4, No.2 , 2014 ,72-79.

[11] Priya T. and Ramachandran T., Anti fuzzy PS-ideals in PS-algebras and its level subsets, International Journal of Mathematical Archive, Vol.5, No.4, 2014, 1-7.

[12] Priya T. and Ramachandran T., Normalisation of fuzzy PS-algebras, International Journal of Engineering Research and Applications, Communicated.

[13] Priya T. and Ramachandran T., On Pseudo fuzzy PS-algebras, Annals of Pure and Applied Mathematics, Communicated.

[14] Sithar Selvam P.M.,Priya T.and Ramachandran T, Anti Q- Fuzzy KU -Ideals in KU - Algebras and its lower level cuts, International journal of Engineering Research \& Applications, volume -2 (4),2012, 1286-1289.

[15] Zadeh. L.A.Fuzzy sets, Information and Control, 8, 1965, 338-353. 